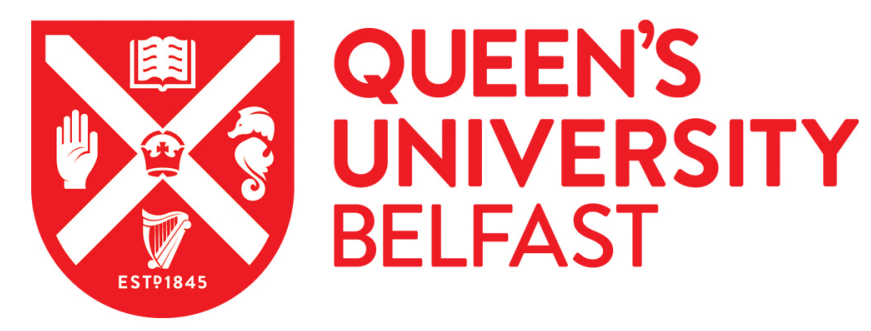

\title{
Comparative Oxygen Consumption of Gastropod Holobionts from Deep-Sea Hydrothermal Vents in the Indian Ocean
}

Sigwart, J. D., \& Chen, C. (2018). Comparative Oxygen Consumption of Gastropod Holobionts from Deep-Sea Hydrothermal Vents in the Indian Ocean. The Biological bulletin, 235(2), 102-112.

https://doi.org/10.1086/699326

Published in:

The Biological bulletin

Document Version:

Peer reviewed version

Queen's University Belfast - Research Portal:

Link to publication record in Queen's University Belfast Research Portal

Publisher rights

Copyright 2018 University of Chicago Press. This work is made available online in accordance with the publisher's policies. Please refer to any applicable terms of use of the publisher.

\section{General rights}

Copyright for the publications made accessible via the Queen's University Belfast Research Portal is retained by the author(s) and / or other copyright owners and it is a condition of accessing these publications that users recognise and abide by the legal requirements associated with these rights.

Take down policy

The Research Portal is Queen's institutional repository that provides access to Queen's research output. Every effort has been made to ensure that content in the Research Portal does not infringe any person's rights, or applicable UK laws. If you discover content in the Research Portal that you believe breaches copyright or violates any law, please contact openaccess@qub.ac.uk. 


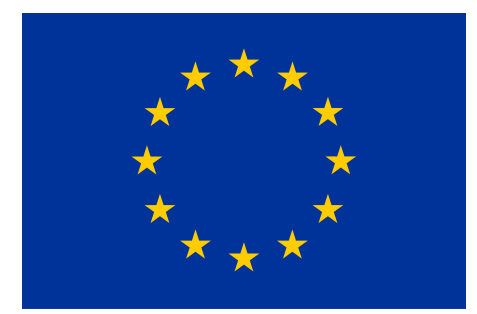

This project has received funding from the European Union's Horizon 2020 research and innovation programme under the Marie Skłodowska-Curie grant agreement No H2020-MSCAIF-2014-655661.

This copy of the accepted manuscript is provided to enable dissemination through Open Access to the scientific data; the version of record is that provided by the publishers. 


\section{Abstract}

19 Physiological traits are the foundation of an organism's success in a dynamic environment, yet basic measurements are unavailable for many taxa and even ecosystems. We measured routine metabolism in two hydrothermal vent gastropods, Alviniconcha marisindica $(\mathrm{n}=40)$ and the scaly-foot gastropod Chrysomallon squamiferum $(\mathrm{n}=18)$, from Kairei and Edmond vent fields on the Central Indian Ridge (23-25 $\mathrm{S}$, approx. 3,000 $\mathrm{m}$ depth). No previous studies have measured metabolism in any Indian Ocean vent animals. After recovering healthy animals to the surface, we performed shipboard closed-chamber respirometry experiments to compare oxygen uptake at different temperatures $\left(10,16,25^{\circ} \mathrm{C}\right.$

${ }^{\circ}$ ) at surface pressure (1 atm). The physiology of these species is driven by the demands of their chemoautotrophic symbionts. Chrysomallon has very enlarged respiratory and circulatory systems, and endosymbionts housed in its trophosome-like internal esophageal gland. By contrast, Alviniconcha has chemoautotrophic bacteria within the gill, and less extensive associated anatomical adaptations. Thus, we predicted that routine oxygen consumption of Chrysomallon might be higher than Alviniconcha. However, oxygen consumption of Chrysomallon was not higher than Alviniconcha, and further Chrysomallon maintained a steady metabolic demand in two widely separated experimental temperatures, while Alviniconcha does not. We interpret these findings to indicate that 1) the trophosome does not fundamentally increase oxygen requirement compared to other gastropod holobionts, and 2$)$ cold temperatures $\left(10^{\circ} \mathrm{C}\right)$ induced a stress response in Alviniconcha resulting in aberrantly high uptake. While these two large gastropod species co-occur, differences in oxygen consumption may reflect the separate niches they occupy in the 41 vent ecosystem. 
Hydrothermal vent ecosystems occur on geologically active tectonic margins on the seafloor, worldwide (Baker et al., 2016; Beaulieu, 2017). While deep-sea vent systems are globally united by a suite of challenging abiotic conditions - no sunlight, highly acidic and toxic vent fluid emerging at superheated temperatures - most vent species are restricted to a particular biogeographic province (Rogers et al., 2012). The region of the East Pacific Rise included the site of the first vent system ever discovered (Corliss et al., 1979), and its fauna remains by far the best studied and most familiar (Mullineaux, 2014). The fast-spreading EPR is characterized by high turnover and geologically unstable chimney structures (Shank et al., 1998; Govenar et al., 2004). By contrast, the Indian Ocean has a markedly different geology, and different fauna, and is so far still relatively unexplored. The slow-to-intermediate-spreading Central Indian Ridge vent fields are characterized by highly stable, complex chimney structures with very little accumulation of mineral material or change (Van Dover et al., 2001; Nakamura et al., 2012; Chen et al., 2015a; Watanabe and Beedessee, 2015). This contrast in abiotic environmental context, and its interplay with the evolutionary history of various clades, underlies the diverse and non-overlapping faunas of different regional vent systems (Ramirez-Llodra $e t$ al., 2007; Rogers et al., 2012).

Hydrothermal vent ecosystems are universally driven by chemosynthesis; in absence of sunlight, primary productivity is drawn from chemoautotrophic microbes that derive energy from the oxidation of hydrogen sulfide, methane, or a variety of other inorganic reducing agents (Stewart et al., 2005). While chemoautotrophic microbes were quickly recognized as the foundation of vent ecosystems, early interpretations clearly assumed that the only way for animals to engage in a bacterially-based food chain was through direct consumption (Jannasch and Wirsen, 1979). The discovery of symbionts within the internal trophosome tissue of the giant tubeworm Riftia pachyptila Jones, 1981 solved the mystery of how this and many other animal species function with reduced or absent digestive systems (Cavanaugh et al., 1981). Dependency on microbes for energy production has led to the evolution of symbiotic relationships in many vent-endemic 
74 animals that directly harness energy production by bacteria (Dubilier et al., 2008). These

75 symbiotic relationships underpin major anatomical and physiological adaptations in these

76 lineages.

78 Vent animals that acquire energy through chemosymbiosis have higher oxygen demands than other non-symbiotic species in the same environment (Girguis and Childress, 2006).

80 Variation in metabolic rates among holobionts are generally correlated to growth rates,

81 and to the availability of reducing agents for biochemical pathways (Childress and

82 Girguis, 2011). A broad range of animals, in many ecosystems, have chemosymbiotic

83 relationships with microbes, but in hydrothermal vent ecosystems only siboglinid

84 annelids, and mollusks (gastropods and bivalves) have intracellular sulfur-oxidizing

85 symbionts (Childress and Girguis, 2011).

Among vent mollusks, almost all species that house chemoautotrophic endosymbionts do so within the tissue of the gill (Dubilier et al., 2008). The only mollusks so far described with internal endosymbionts are two lineages of Indian Ocean vent gastropods, which house endosymbionts in an internal trophosome-like organ that is a hypertrophied oesophageal gland (Chen et al., 2015b; Chen et al., 2017). These two genera, Chrysomallon, and Gigantopelta, are both unusually large ( $\sim \mathrm{cm}$ adult shell length) compared to the majority of vent gastropod taxa $(\sim 1 \mathrm{~cm})$. Large body sizes are related to their housing endosymbiosis (Vermeij, 2016) but not uniquely associated with the 'trophosome'. There are other, similarly sized large-bodied vent gastropods, in the provannid genera Alviniconcha and Ifremeria. Species in these two genera have chemoautotrophic endosymbionts in the gill that contribute to most of the host's metabolic requirements (Warén and Bouchet, 1993; Beinart et al., 2014); dependency on symbionts apparently enables the animals to reach large adult sizes (Henry et al., 2008).

100 While the 'outcome' of large adult size in the holobiont is similar, these lineages

101 represent two profoundly different strategies to house endosymbionts: on gill tissue in

102 contact with the water, or in internal tissue within the visceral mass. 
104 Trophosome structures in the genera Chrysomallon (the scaly-foot gastropod) and

105 Gigantopelta are accompanied by other substantial anatomical adaptations, similar to

106 those in siboglinid tubeworms, which alter the configuration and life history of the host to

107 create an optimized environment for the microbes. These adaptations include enlarged

108 circulatory systems with a muscular ventricle that acts as a pumping heart, unlike any

109 other gastropod mollusk (Supplementary Video 1). Like siboglinids, the gastropod

110 trophosome tissues are highly vascularized (Chen et al., 2015b), which anatomically

111 suggests the circulatory system is adapted to supply oxygen and potentially hydrogen

112 sulfide to the bacteria. There are clear parallels to the well-studied anatomy and

113 physiology of Riftia and other tubeworms; however, the physiology and even growth

114 rates of Chrysomallon and Gigantopelta remain undescribed.

115 Alviniconcha marisindica Okutani in Johnson et al., 2014 (with symbionts in its gill) and

116 the scaly-foot gastropod Chrysomallon squamiferum Chen et al., 2015 (with symbionts in

117 an internal trophosome) co-occur at vent sites in the Central Indian Ocean (Johnson et al.,

118 2014; Watanabe and Beedessee, 2015). This presents an interesting opportunity for

119 comparative physiology, to test the metabolic effects of these two different evolutionary

120 strategies to harness energy from vents through endosymbiosis, in the gill (in

121 Alviniconcha) or within a trophosome (in Chrysomallon). In the present study, we

122 conducted experiments to measure the oxygen uptake rates of these two species in a

123 range of temperatures. This is the first study of metabolism in Indian Ocean hydrothermal

124 vent animals. We predicted that the oxygen demand of Chrysomallon might be higher

125 than that for Alviniconcha. Chemosymbiosis, used by both taxa, is related to increased

126 oxygen requirements (Childress and Girguis, 2011), but the trophosome may represent a

127 more extreme dependency on microbial symbionts and thus further increased oxygen

128 demand.

129

130 Materials and Methods

132 Gastropods were collected at two hydrothermal vents sites on the Central Indian Ridge by

133 the human-occupied submersible (HOV) Shinkai 6500 using a suction slurp gun during

134 the R/V Yokosuka cruise YK16-E02. Most specimens were collected at the Kairei vent 
135 field $\left(25^{\circ} 19.2253^{\prime} \mathrm{S}, 70^{\circ} 2.4217^{\prime} \mathrm{E}\right.$, depth $\left.2420 \mathrm{~m}\right)$ and a smaller population from the 136 Edmond vent field (2352.6823' S, 69³5.8013' E, depth $3280 \mathrm{~m})$. The scaly-foot

137 gastropod Chrysomallon squamiferum was found only at the Kairei vent field, co-

138 occurring with $A$. marisindica (Table 1). Specimens were allowed one to two days of

139 acclimation to lab conditions in aquaria at surface pressure and light.

140

141 Animals were housed in static aquaria in a constant temperature room in filtered seawater

142 that was changed several times daily (more frequently in higher temperature groups).

143 Two experimental temperatures were used: $25^{\circ} \mathrm{C}\left(24.58 \pm 0.150\right.$ s.d. ${ }^{\circ} \mathrm{C}$ over all

144 experiments $), 16{ }^{\circ} \mathrm{C}\left(16.49 \pm 0.128\right.$ s.d. ${ }^{\circ} \mathrm{C}$ over all experiments $)$, and $10{ }^{\circ} \mathrm{C}(10.51 \pm$

1450.300 s.d. ${ }^{\circ} \mathrm{C}$ over all experiments). These were selected as relevant to the reported range

146 of habitat temperatures particularly for Alviniconcha, $5-33{ }^{\circ} \mathrm{C}$ (fide Warén and Bouchet,

147 1993) and data measured in situ from the water of gastropod colonies during sampling for

148 this study, mainly from $10-21{ }^{\circ} \mathrm{C}$ but up to a maximum of $38^{\circ} \mathrm{C}$ (Table 1; Takai et al.,

149 2016).

150

151 Closed-chamber respirometry experiments at surface pressure (1 atm) were used to

152 measure oxygen consumption as a proxy for metabolic rate, following the methods of

153 Carey et al. (2013). Animals were placed into individual Perspex chambers filled with

154 filtered seawater at the experimental temperature; chambers were sealed with a rubber-

155 gasket stopper and fitted with a fiber-optic oxygen probe (FOXY systems, Ocean Optics,

156 Dunedin, Florida). Oxygen and temperature data were recorded continuously at intervals

157 of $1 \mathrm{~s}$. Probes were calibrated using a two-point calibration to air-saturated experimental

158 filtered seawater ( $100 \%$ oxygen saturation) and $5 \% \mathrm{Na}_{2} \mathrm{SO}_{3}$ in seawater $(0 \%$ oxygen

159 saturation). Calibrations were re-set every 24 hours, and checked at the start and end of

160 each experiment, but there was no drift requiring correction. Six trials were run in parallel

161 with one empty chamber in each set serving as a control to measure potential microbial

162 consumption of oxygen in the experimental seawater. Experiments were run for up to 7

163 hours depending on specimen size and activity; most experiments took 3-4 hours to

164 decrease to $60 \%$ of air-saturated conditions (with shorter times at higher temperatures). 
Specimens were not re-used at different temperatures; each animal was used in only one

166 experiment.

Respiratory rates $\left(\mathrm{VO}_{2}, \mathrm{mgO}_{2} \cdot \mathrm{h}^{-1}\right)$ were calculated for each specimen from the average rate at which oxygen tension decreased, to measure routine oxygen consumption rate. These measurements were taken below $95 \%$ air-saturation and as early in the trial as possible, selected for periods with the smallest possible fluctuation in temperature and using the same time period for each set of six parallel trials. Recordings with substantial fluctuations and aberrant measurements were discarded. Thus the number of specimens used for analysis Air-saturated $\mathrm{O}_{2}$ concentration $\left(\mathrm{mg} \cdot \mathrm{L}^{-1}\right)$ was calculated according to Benson and Krause (1984) using the surface salinity measured by the ConductivityTemperature-Depth profiler of the HOV Shinkai 6500 on the date of collection (31.3) and average temperature in each experiment (e.g. $8.08 \mathrm{mg} \cdot \mathrm{L}^{-1}$, for $16.53{ }^{\circ} \mathrm{C}$ and 31.3 salinity). Recordings from empty chambers were used as a control, to estimate a background rate of microbial activity. The rate of background oxygen consumption in the control apparatus was subtracted from each experimentally trial rate to determine $\mathrm{VO}_{2}$ for each subject. As these experiments were conducted at sea, it was not possible to determine precise wet weights of the live animals; at termination of the experiments, subjects were immediately frozen at $-80^{\circ}$ for preservation and later weighed. Mass-specific oxygen uptake $\left(\mathrm{MO}_{2}, \mu \mathrm{mol} \mathrm{O} \mathrm{O}_{2} \cdot \mathrm{g}^{-1} \cdot \mathrm{h}^{-1}\right)$ was calculated for each subject from the individual $\mathrm{VO}_{2}$ and wet weight. We calculated a linear ordinary least squares regression from log-log transformed data to determine an approximate metabolic scaling exponent for Alviniconch $a$, finding $b$ in a standard equation for metabolic rate (r) scaling with animal

192 Because sample sizes were relatively small, and not balanced among experimental groups

193 (species and temperatures), a generalized linear model approach was used to compare

194 central tendency among groups implemented in R (R Core Team, 2017). The GLM

195 compared $\mathrm{MO}_{2}$, as the response variable, and species and temperature as factors, using a 
196 Gaussian link function (function ' $\mathrm{glm}$ ' in R). Additional pairwise comparisons among

197 groups were performed using the Mann-Whitney U test.

\section{Results}

201 Experimental animals of both species appeared to be in good condition at surface

202 pressure, readily attached to the side of respirometry chambers, and remained responsive

203 (Fig. 1). Chrysomallon squamiferum specimens were active and explored their aquarium

204 environment and did not show any behaviorally obvious signs of stress from transitions in

205 pressure and temperature. A total of 55 Chrysomallon specimens were collected in one

206 sampling event at Kairei field, some of which were used for respirometry. Because

207 Chrysomallon was collected in only one event, at the end of the cruise, only two

208 temperature treatments could be accommodated. Alviniconcha marisindica were collected

209 in much larger numbers, from two sites (approximately 300 specimens from each of

210 Kairei and Edmond fields, among several sampling events), though subsets of animals in

211 good condition were used for these experiments (Table 1; Table 2). Some Alviniconcha

212 specimens were observed to purge material from the pallial chamber, which had the

213 appearance of a mixture of mucous, and bacterial mats; this was particularly observed in

214 animals at $10^{\circ} \mathrm{C}$ (Fig. $1 \mathrm{C}$, note condensation on the respirometry chamber surface from

215 chilled seawater).

217 An analysis of deviance, using chi-squared goodness of fit, indicated significant effects of

218 both species $(p=0.0088)$ and temperature $(p=0.027)$ for mass-specific oxygen uptake

$219\left(\mathrm{MO}_{2}, \mu \mathrm{mol} \mathrm{O}{ }_{2} \cdot \mathrm{g}^{-1} \cdot \mathrm{h}^{-1}\right)$. The metabolic rates of Chrysomallon were not significantly

220 different between high $\left(25^{\circ} \mathrm{C}\right.$ : mean $\left.\mathrm{MO}_{2} 0.809 \pm 0.158 \mathrm{~s} . \mathrm{d} . \mu \mathrm{mol} \cdot \mathrm{g}^{-1} \cdot \mathrm{h}^{-1}\right)$ and low $(10$

$\left.221{ }^{\circ} \mathrm{C}: 0.854 \pm 0.113 \mu \mathrm{mol} \cdot \mathrm{g}^{-1} \cdot \mathrm{h}^{-1}\right)$ temperature trials $(\mathrm{W}=44, p=0.76$; Fig. $2 \mathrm{~A})$. Metabolic

222 rates in Alviniconcha were similar at $25^{\circ} \mathrm{C}$ and $16{ }^{\circ} \mathrm{C}$, and not significantly different

223 between those two temperature treatments $(\mathrm{W}=86, p=0.61)$ or to the Chrysomallon

224 rates $(\mathrm{W}=289, p=0.12)$. That is, among data recorded for the five treatment groups (two

225 temperatures for Chrysomallon and three for Alviniconcha), the metabolic rates were not

226 significantly different among four out of five in pairwise comparisons (Fig 2A). 
228 The metabolic rate in Alviniconcha in the low temperature treatment $\left(10^{\circ} \mathrm{C}\right)$ was much

229 higher than any other experimental group (mean $\mathrm{MO}_{2} 2.108 \pm 0.287 \mu \mathrm{mol} \cdot \mathrm{g}^{-1} \cdot \mathrm{h}^{-1}$; Fig.

230 2A). This is substantially higher than the $16^{\circ} \mathrm{C}$ treatment $(\mathrm{W}=43, p=0.066)$ and

231 significantly higher compared to the $25{ }^{\circ} \mathrm{C}$ treatment for Alviniconcha $(\mathrm{W}=187, p=$

232 0.0026). It is also significantly higher than the Chrysomallon rates $\left(\mathrm{W}=153, p=4 \cdot 10^{-5}\right)$.

234 The $25^{\circ} \mathrm{C}$ temperature treatment included data from two separate populations of

235 Alviniconcha, collected at the two vent fields. However, there was no significant

236 difference in the mean values for data from the two fields ( $\mathrm{W}=86, p=0.6475)$ and no

237 evident trend that separated their metabolic responses (Fig. 2B). The regression results

238 indicated an approximate scaling exponent of 0.25 for Alviniconcha in the form $\mathrm{r}=$

$239 \quad 1.7 \cdot \mathrm{M}^{-0.25}\left(\mathrm{R}^{2}=0.31\right)$.

240

241

Discussion

242

The thermal context of vent habitats

245 Hydrothermal vent ecosystems are characterized by steep temperature gradients, from

246 near freezing ambient temperatures on the sea floor to superheated vent effluent

247 temperatures measured at $361.4^{\circ} \mathrm{C}$ (Kairei field) and $375.4^{\circ} \mathrm{C}$ (Edmond field) during the

248 dives that sampled specimens used here (Takai et al., 2016). The continuous eruption of

249 vent fluid creates a turbid environment with fine scale but extreme fluctuations in

250 chemistry and temperature (Johnson et al., 1988). In contrast to other deep-sea habitats

251 the chimney surface is typically hot, with water temperatures more similar to tropical

252 shallow water environments than abyssal seas (Childress and Mickel, 1985). Yet turbid

253 changes in temperature and the steep thermal gradient to ambient water mean that

254 exposure to temperatures over $40-50{ }^{\circ} \mathrm{C}$ is probably relatively rare and transient (Girguis

255 and Lee, 2006).

256

257 Certain patches within vent habitats experience high amplitude fluctuations but this does 
not imply homogenization of the abiotic conditions. Local characteristics of temperature, chemistry, and hydrodynamics within vent sites create microhabitats and some species are potentially adapted to narrowly defined niches (Bates et al., 2005; Bates et al., 2010; Podowski et al., 2010; Beinart et al., 2015). Based on the patchy distribution and high local biomass in localized colonies, vent endemic animals like Chrysomallon and Alviniconcha are inferred to be constrained to a niche with characteristic chemistry and temperature. During the cruise that obtained the animals used in these experiments, samples were taken from within the gastropod colony masses to measure water temperature and chemistry in situ. The temperatures taken on these dives are as accurate as possible but still gave a very broad range, from 5 to $20^{\circ} \mathrm{C}$ in a single Alviniconcha colony (Takai et al., 2016).

Previous studies at Kairei vent field reported a temperature of $2-4{ }^{\circ} \mathrm{C}$ around Alviniconcha (Suzuki et al., 2006), but those data reflect ambient conditions in the vicinity of the chimney surface, and not directly measured in situ water temperature of the gastropod colony. Additional specimens of A. marisindica kept at $4{ }^{\circ} \mathrm{C}$ in our laboratory were noticeably lethargic and unresponsive. Only specimens from the Kairei field were tested at low temperatures, but we were able to complete experiments with large sample sizes in two temperatures for both fields, and found no site-specific differences in metabolic rates.

\section{Stress effects and thermal optima}

Both experimental species survived the transition to surface pressure, and behaved apparently normally in laboratory conditions in the shipboard laboratory. Chrysomallon squamiferum suffered no mortalities, and appeared much more robust to captivity but were kept for a shorter period than Alviniconcha marisindica. Other work on Alviniconcha sp. found the animals unable to tolerate laboratory maintenance (pressurized) for more than a few days (Henry et al., 2008). Among our samples of Alviniconcha marisindica (several hundred individuals) the smaller juvenile animals had higher levels of activity as observed in aquaria, as well as higher metabolic rates in line 
with expectations from allometric scaling of metabolism. These smaller individuals were

290 perhaps more able to cope with the stress of captivity.

292 Despite short-term survivorship, the animals we used were certainly compromised during 293 experimental trials, especially at lower temperatures. Several Alviniconcha specimens

294 were excluded from experimental trials because they appeared to be stressed. We

295 frequently observed larger individuals of Alviniconcha marisindica purging what

296 appeared to be bacterial mats from the pallial cavity. This may speculatively have been

297 symptomatic of bleaching of the microbial symbionts associated with the gill; if true,

298 would be a clear indication of environmental stress for host and symbiont. We are not

299 certain whether the behavior observed was bleaching but it is certainly possible, a

300 comparable experience to coral bleaching under acute thermal stress (e.g., Fujise et al.,

301 2014). Bleaching also occurs among other mollusks: some bivalves host exocellular

302 photosymbiotic dinoflagellates (Vermeij, 2013), and can also experience bleaching under

303 thermal stress, reduced salinity, or excessive light exposure (Norton et al., 1995; Buck et

304 al., 2002; Maboloc et al., 2015). Bleaching damages the metabolic capacity of the host

305 and reduces fitness, fecundity, and survival, but is not lethal. By comparison with energy-

306 harnessing photo-endosymbionts in other systems, vent mollusks could also potentially

307 lose their symbiotic microbes when stressed.

309 In general, higher temperatures lead to higher metabolic rates in ectotherms like

310 gastropod mollusks. But gastropods can respond to transient environmental stress either

311 through increasing oxygen consumption or a hypometabolic dormant state. Previous

312 studies have shown that hydrothermal vent organisms do not necessarily demonstrate a

313 straightforward relationship between ambient temperature and metabolic rate (Girguis et

314 al., 2002; Henry et al., 2008). In several cases, other vent animals demonstrated an

315 apparent optimum temperature with peak metabolic rate, with relatively depressed

316 activity at higher and lower temperatures (e.g., Riftia pachyptila in Girguis et al., 2002).

318 Temperature has a strong control over metabolic rate in vent gastropods (Childress and

319 Mickel, 1985), but based on available data for other species of vent invertebrates 
including gastropods, those responses are evidentially difficult to predict a priori. We reviewed prior literature on physiology of vent endemic invertebrates to find comparative measurements obtained at the same temperatures as used herein (Fig. 2). We are able to make direct comparison to data for two other gastropods, Ifremeria nautilei and Alviniconcha sp. to our higher temperature treatment (Henry et al., 2008). Across a range of temperatures, Henry and colleagues (2008) found that Alviniconcha sp. had variable metabolic rates, from a low of around $2 \mu \mathrm{mol} \mathrm{g}{ }^{-1} \mathrm{hr}^{-1}$ at $5{ }^{\circ} \mathrm{C}$ to rates over $7 \mu \mathrm{mol} \mathrm{g} \mathrm{gr}^{-1}$ with a maximum in a treatment at $19{ }^{\circ} \mathrm{C}$ and lower rates at higher temperatures; Ifremaria nautilei, by contrast, showed little variation with temperature, although these experiments had limited sample sizes. The rate of oxygen consumption recorded for Alviniconcha sp. at $\sim 25{ }^{\circ} \mathrm{C}$ in those experiments is much higher than our results, while the mean rate they reported for Ifremeria nautilei is very similar to measurements we obtained for both Alviniconcha marisindica and Chrysomallon squamiferum (Figure 2B).

Data in Henry et al. (2008) were based on animals collected from Lau Basin, where there are three Alviniconcha species, which were taxonomically revised after those experiments were published (Johnson et al., 2014). It is not possible to determine which species (whether singular or perhaps plural) contributed to those data. Species determination is important, since superficially similar species can have distinctly different metabolic rates related to what might seem to be minor differences in life history (e.g. Carey et al., 2013). Although the congeneric Alviniconcha sp. is clearly closely related to the species we examined, unfortunately it is unclear how much variation should be expected within species or among similar and congeneric species.

While a thermal optimum measured for individuals of a species is likely connected to the thermal regime in their niche within the vent system, laboratory effects also impact measurements of metabolic activity. Alviniconcha sp. experienced lethal effects above 35 ${ }^{\circ} \mathrm{C}$, but freshly collected specimens were more tolerant to higher temperatures (Henry et $a l ., 2008)$. This is reflective of a broader pattern, that vent animals under additional stress, including decreased pressure, are tolerant to a narrower thermal range (e.g., Mickel and Childress, 1982a; Mickel and Childress, 1982b). Early measurements in situ at 2,600 m 
found that the vent bivalve Calyptogena magnifica Boss \& Turner, 1980 was a strong oxyregulator, but that metabolic rates of captive animals were relatively depressed (Arp et al., 1984). Smaller vesicomyid species, Calyptogena elongata Dall, 1916 and Calyptogena pacifica Dall, 1891, also showed much lower mass specific metabolic rates (Childress and Mickel, 1985). A number of vent species show a narrow temperature band with maximum metabolic rate, and rapidly decreasing oxygen consumption at higher or lower temperatures outside that optimum. For example, Alviniconcha sp. from the Western Pacific had a thermal optimum at between $20-25^{\circ} \mathrm{C}$ where they had the highest oxygen consumption, and gradually decrease either side of that temperature (Henry et al., 2008). Riftia has a higher thermal optimum at $25-27^{\circ} \mathrm{C}$, represented by a peak in oxygen, $\mathrm{CO}_{2}$, and $\mathrm{H}_{2} \mathrm{~S}$ consumption, compared to a gradual decline in uptake at lower temperatures or a sharp drop at temperatures over $30^{\circ} \mathrm{C}$ (Girguis et al., 2002).

Chrysomallon squamiferum has very enlarged respiratory and circulatory systems, adaptations to provide oxygen to endosymbionts housed in its trophosome-like internal esophageal gland (Chen et al., 2015b). The fact that we found no significant difference in oxygen consumption at two very different temperatures in $C$. squamiferum may be evidence that species is more robust than Alviniconcha to a wider thermal range. However, it is also possible that Chrysomallon would have a higher metabolic rate between 10 and $25{ }^{\circ} \mathrm{C}$. Given that the in situ point measurement for temperature was relatively low (as low as $10{ }^{\circ} \mathrm{C}$; Table 1), it is unlikely that the thermal optimum for this species is any higher than $25^{\circ} \mathrm{C}$. The closest comparators available in the literature are the gastropods Alviniconcha and Ifremeria, and another organism with a large trophosome, the tubeworm Riftia; these organisms all have maximum uptake rates at relatively high temperatures, closer to our experiments at $25^{\circ} \mathrm{C}$. Based on comparison to data from other Alviniconcha sp., and the best available measurements of temperature within the colony mass, we infer that the elevated metabolic rate recorded for Alviniconcha marisindica at $10{ }^{\circ} \mathrm{C}$ is not a thermal optimum, but represents a response to stress from unusually low temperature. The gradation of temperatures available here is not fine enough to draw any further conclusions about thermal optima, and there is the further consideration of the interaction of temperature and pressure on metabolism. 
383 To facilitate effective oxygen extraction and consumption, Alviniconcha spp. has an

384 increased surface area of the gill and use a combination of high oxygen affinity

385 hemocyanins (for most of the body) and hemoglobin (for gill where symbionts are

386 located); the gill of of Alviniconcha hessleri contains hemoglobins at relatively high

387 concentrations (Wittenberg and Stein, 1995). Chrysomallon also has much increased gill

388 surface area for oxygen extraction and a very large volume of blue blood which indicates

389 usage of hemocyanin for oxygen transportation (Chen et al., 2015b). These are

390 convergent with the same features in vent annelids including Riftia (e.g. Andersen et al.,

391 2002). Substantial work remains to understand the similarities and differences of these

392 aspects of respiration among vent holobionts.

394 The oxygen binding affinity of hemoglobin and hemocyanin — and hence oxygen

395 metabolism - are directly affected by both temperature and pressure (Arp et al., 1984;

396 Childress et al., 1993; Girguis et al., 2002; Girguis and Childress, 2006; Girguis \& Lee,

397 2006). Much of the other past work on the physiology of vent organisms was conducted

398 in pressurized aquaria; after the animals were recovered to the surface (exactly as in our

399 experiments) they were secondarily transferred to a pressurized system and re-pressurized

400 to match their natural depth before respirometry measurements were conducted (see

401 schematics in e.g., Quetin and Childress, 1980; Kochevar et al., 1992). Conducting

402 experimental measurements at surface pressure reduces the interference with the animal

403 subjects, but diminishes comparability with past work and their natural environment. The

404 available literature on the physiology of vent organisms is sparse, especially in

405 comparison to the biodiversity of vent endemic species. A number of other studies

406 conducted at surface pressure are not directly comparable because of differences in

407 technique, for example oxygen consumption reported per individual organism rather than

408 wet tissue mass limits the comparative power (Koike et al., 1988; Fujikura et al., 1993).

409 There is clearly a metabolic response to shifting ambient temperature, as demonstrated in

410 the crab Bythograea thermydron which increased oxygen consumption at surface

411 pressure compared to experiments in a re-pressurized system at a range of temperature

412 (Mickel and Childress, 1982a). That metabolic increase was not an effect of pressure on 
413 oxygen metabolism per se, which would predict a decreased rate due to lower oxygen

414 binding affinity, but rather the sublethal effects of the neuromuscular system that increase

415 individual oxygen demand (Mickel and Childress, 1982b). Given the possibility of such

416 stress responses, low-pressure effects do not necessarily account for relatively low

417 metabolic rate in the gastropod species studied here.

\section{Conclusions}

421 In the context of hydrothermal vent environments, which are complex, dynamic, and

422 inaccessible, it is particularly difficult to measure temperature with sufficiently fine

423 spatial detail to understand the abiotic environment as another species would experience

424 it. Vent endemic species are often characteristically constrained to a very narrow

425 environment in space and time. Hydrothermal vents on slower spreading ridges such as

426 those in the Indian Ocean are much more stable in comparison to those on faster

427 spreading systems such as the East Pacific Rise (Lalou et al., 1993; Copley et al., 2016).

428 Gastropod colonies of the species we studied comprise hundreds or thousands of animals

429 occupying $1 \mathrm{~m}^{2}$ or less. The scaly-foot gastropod colony sampled herein was found in the

430 same, previously recorded location from 2001 (see Suzuki et al., 2006), indicating that it

431 has not moved or shifted on a scale of decades. There is evidentially a specific

432 environment of temperature, flow, and water chemistry in that space that characterizes

433 the niche of that species.

435 Further work on temperature tolerance would be beneficial to understand the boundaries

436 of the niches of vent endemic species, both in terms of metabolic performance (e.g.,

437 Henry et al., 2008; Beinart et al., 2015) and behavioral choices (e.g., Bates et al., 2005;

438 Girguis and Lee, 2006). Previous research has mostly focused on species from the better

439 studied East Pacific Rise (with some additional examples from the Western Pacific back-

440 arc basins), and the Indian Ocean presents a very different geological context. Niche

441 specificity limits the dispersal potential of organisms. If a species is constrained in a

442 small niche but nonetheless need to disperse pelagically to maintain connectivity between 
443 vent fields, then it is limited as not all vent fields may contain the specific niche required 444 by that species.

446 We found different metabolic responses of two co-occurring vent gastropods with notably

447 different symbiont-housing mechanisms. Interestingly, the trophosome anatomy of

448 Chrysomallon does not fundamentally increase oxygen requirement compared to other

449 gastropod holobionts. This fits with a general model that the scaly-foot gastropod

450 adaptations - including a reduced, non-ganglionated nervous system as well as the large,

451 well-developed trophosome - render it a vessel for its symbionts, and its physiology

452 may buffer the bacteria from environmental fluctuations. By contrast, Alviniconcha has

453 no way of protecting its symbionts housed in the gill epithelium which comes in direct

454 contact with vent fluid, resulting in the speculative putative bleaching symptoms under

455 stress.

457 Based on the evidence reported here, it is possible that the optimum metabolic

458 performance of the scaly-foot gastropod would be found between the high and low

459 temperatures we were able to use. However, based on the respirometry trials and the

460 observed behavior of the captive animals, it is possible that Chrysomallon may simply be

461 more robust to a wider range of environmental conditions. The limits of these species'

462 tolerance remains an important question, because differential abiotic ranges could be

463 taken as evidence that niches are defined as much by biotic competition as by

464 physiological constraint.

\section{Acknowledgements}

We thank the pilots and the operation team of the HOV Shinkai 6500, as well as the

469 Captain and crews of the R/V Yokosuka, for their tireless support of the scientific activity

470 at sea during the research cruise YK16-E02. The principal scientist of YK16-E02, Dr Ken

471 Takai (JAMSTEC), is gratefully acknowledged for his diligent execution of the cruise.

472 We are especially grateful to Dr Leigh Marsh (University of Southampton) who helped

473 with setting up on-board experiments and dissections, and to Prof. Brad Seibel 
474 (University of South Florida) and Dr Janet Voight (The Field Museum, Chicago) for their 475 insightful discussion and comments. The comments of two anonymous reviewers

476 improved an earlier version of this article. This research was supported by the European

477 Commission award H2020-MSCA-IF-2014-655661 to JDS, and a JAMSTEC

478 International Postdoctoral Fellowship to CC.

479

480 


\section{Literature Cited}

Andersen, A.C., Jolivet, S., Claudinot, S. and Lallier, F.H. 2002. Biometry of the branchial plume in the hydrothermal vent tubeworm Riftia pachyptila (Vestimentifera; Annelida). Can. J. Zool. 80: 320-332.

Arp, A. J., J. J. Childress, and C. R. Fisher. 1984. Metabolic and blood gas transport characteristics of the hydrothermal vent bivalve Calyptogena magnifica. Physiol. Zool. 57: 648-662.

Arp, A. J., M. L. Doyle, E. Di Cera, and S. J. Gill. 1990. Oxygenation properties of the two co-occurring hemoglobins of the tube worm Riftia pachyptila. Respir. Physiol. 80: 323-334.

Baker, E. T., J. A. Resing, R. M. Haymon, V. Tunnicliffe, J. W. Lavelle, F. Martinez, V. Ferrini, S. L. Walker, and K. Nakamura. 2016. How many vent fields? New estimates of vent field populations on ocean ridges from precise mapping of hydrothermal discharge locations. Earth Planet. Sci. Lett. 449: 186-196.

Bates, A. E., R. W. Lee, V. Tunnicliffe, and M. D. Lamare. 2010. Deep-sea hydrothermal vent animals seek cool fluids in a highly variable thermal environment. Nat. Commun. 1: 14.

Bates, A. E., V. Tunnicliffe, and R. W. Lee. 2005. Role of thermal conditions in habitat selection by hydrothermal vent gastropods. Mar. Ecol. Prog. Ser. 305: 1-15.

Beaulieu, S. E. 2017. InterRidge Global Database of Active Submarine Hydrothermal Vent Fields: Version 3.4, Accessed 2017-12-30. InterRidge, Institut de Physique du Globe de Paris (IPGP), France: http://vents-data.interridge.org.

Beinart, R. A., A. Gartman, J. G. Sanders, G. W. Luther, and P. R. Girguis. 2015. The uptake and excretion of partially oxidized sulfur expands the repertoire of energy resources metabolized by hydrothermal vent symbioses. Proc. R. Soc. B. 282.

Beinart, R. A., S. V. Nyholm, N. Dubilier, and P. R. Girguis. 2014. Intracellular Oceanospirillales inhabit the gills of the hydrothermal vent snail Alviniconcha with chemosynthetic, $\gamma$-Proteobacterial symbionts. Environ. Microbiol. Rep. 6: 656-664. 
Benson, B. B., and D. Krause. 1984. The concentration and isotopic fractionation of oxygen dissolved in freshwater and seawater in equilibrium with the atmosphere. Limnol. Oceanogr. 29: 620-632.

Buck, B. H., H. Rosenthal, and U. Saint-Paul. 2002. Effect of increased irradiance and thermal stress on the symbiosis of Symbiodinium microadriaticum and Tridacna gigas. Aquat. Living Resour. 15: 107-117.

Carey, N., J. D. Sigwart, and J. G. Richards. 2013. Economies of scaling: More evidence that allometry of metabolism is linked to activity, metabolic rate and habitat. J. Exp. Mar. Biol. Ecol. 439: 7-14.

Cavanaugh, C. M., S. L. Gardiner, M. L. Jones, H. W. Jannasch, and J. B. Waterbury. 1981. Prokaryotic cells in the hydrothermal vent tube worm Riftia pachyptila Jones: Possible chemoautotrophic symbionts. Science 213: 340.

Chen, C., J. T. Copley, K. Linse, and A. D. Rogers. 2015a. Low connectivity between 'scaly-foot gastropod' (Mollusca: Peltospiridae) populations at hydrothermal vents on the Southwest Indian Ridge and the Central Indian Ridge. Org Divers Evol 15: 663670.

Chen, C., J. T. Copley, K. Linse, A. D. Rogers, and J. D. Sigwart. 2015b. The heart of a dragon: 3D anatomical reconstruction of the 'scaly-foot gastropod' (Mollusca: Gastropoda: Neomphalina) reveals its extraordinary circulatory system. Front. Zool. 12: 13 .

Chen, C., K. Uematsu, K. Linse, and J. D. Sigwart. 2017. By more ways than one: Rapid convergence at hydrothermal vents shown by 3D anatomical reconstruction of Gigantopelta (Mollusca: Neomphalina). BMC Evol. Biol. 17: 62.

Childress, J. J., A. J. Arp, and C. R. Fisher. 1984. Metabolic and blood characteristics of the hydrothermal vent tube-worm Riftia pachyptila. Mar. Biol. 83: 109-124.

Childress, J. J., C. R. Fisher, J. A. Favuzzi, A. J. Arp, and D. R. Oros. 1993. The role of a zinc-based, serum-borne sulphide-binding component in the uptake and transport of dissolved sulphide by the chemoautotrophic symbiont-containing clam Calyptogena elongata. J. Exp. Biol. 179: 131.

Childress, J. J., C. R. Fisher, J. A. Favuzzi, R. E. Kochevar, N. K. Sanders, and A. M. Alayse. 1991. Sulfide-driven autotrophic balance in the bacterial symbiont- 
containing hydrothermal vent tubeworm, Riftia pachyptila Jones. Biol. Bull. 180: 135153.

Childress, J. J., and P. R. Girguis. 2011. The metabolic demands of endosymbiotic chemoautotrophic metabolism on host physiological capacities. J. Exp. Biol. 214: 312. Childress, J. J., and T. J. Mickel. 1985. Metabolic rates of animals from the hydrothermal vents and other deep-sea habitats. Bull. Biol. Soc. Wash. 6: 249-260.

Copley, J. T., L. Marsh, A. G. Glover, V. Hühnerbach, V. E. Nye, W. D. K. Reid, C. J. Sweeting, B. D. Wigham, and H. Wiklund. 2016. Ecology and biogeography of megafauna and macrofauna at the first known deep-sea hydrothermal vents on the ultraslow-spreading Southwest Indian Ridge. Sci. Rep. 6: 39158.

Corliss, J. B., J. Dymond, L. I. Gordon, J. M. Edmond, R. P. von Herzen, R. D. Ballard, K. Green, D. Williams, A. Bainbridge, K. Crane, and T. H. van Andel. 1979. Submarine thermal springs on the galápagos rift. Science 203: 1073-1083.

Dubilier, N., C. Bergin, and C. Lott. 2008. Symbiotic diversity in marine animals: the art of harnessing chemosynthesis. Nat. Rev. Microbiol. 6: 725.

Felbeck, H. 1981. Chemoautotrophic potential of the hydrothermal vent tube worm, Riftia pachyptila Jones (Vestimentifera). Science 213: 336.

Fujikura, K., J. Hashimoto, S. Segawa, and Y. Fujiwara. 1993. Thermal tolerance of white blind crab (Bythograeidea) inhabited at hydrothermal vents. JAMSTEC J. Deep Sea Res. 9: 383-391.

Fujise, L., H. Yamashita, G. Suzuki, K. Sasaki, L. M. Liao, and K. Koike. 2014. Moderate thermal stress causes active and immediate expulsion of photosynthetically damaged zooxanthellae (Symbiodinium) from corals. PLoS ONE 9: e114321.

Girguis, P. R., and J. J. Childress. 2006. Metabolite uptake, stoichiometry and chemoautotrophic function of the hydrothermal vent tubeworm Riftia pachyptila: responses to environmental variations in substrate concentrations and temperature. $J$. Exp. Biol. 209: 3516.

Girguis, P. R., J. J. Childress, J. K. Freytag, K. Klose, and R. Stuber. 2002. Effects of metabolite uptake on proton-equivalent elimination by two species of deep-sea vestimentiferan tubeworm, Riftia pachyptila and Lamellibrachia cf. luymesi: proton 
elimination is a necessary adaptation to sulfide-oxidizing chemoautotrophic symbionts. J. Exp. Biol. 205: 3055.

Girguis, P. R., and R. W. Lee. 2006. Thermal preference and tolerance of alvinellids. Science 312: 231.

Goffredi, S. K., J. J. Childress, N. T. Desaulniers, and F. J. Lallier. 1997. Sulfide acquisition by the vent worm Riftia pachyptila appears to be via uptake of $\mathrm{HS}^{-}$, rather than $\mathrm{H}_{2}$ S. J. Exp. Biol. 200: 2609.

Govenar, B., M. Freeman, D. C. Bergquist, G. A. Johnson, and C. R. Fisher. 2004. Composition of a one-year-old Riftia pachyptila community following a clearance experiment: insight to succession patterns at deep-sea hydrothermal vents. Biol. Bull. 207: $177-182$.

Henry, M. S., J. J. Childress, and D. Figueroa. 2008. Metabolic rates and thermal tolerances of chemoautotrophic symbioses from Lau Basin hydrothermal vents and their implications for species distributions. Deep Sea Res., Part I 55: 679-695.

Jannasch, H.W. and C.O. Wirsen. 1979. Chemosynthetic primary production at East Pacific sea floor spreading centers. Bioscience 29: 592-598.

Johnson, K. S., J. J. Childress, and C. L. Beehler. 1988. Short-term temperature variability in the Rose Garden hydrothermal vent field: an unstable deep-sea environment. Deep-Sea Res., Part A 35: 1711-1721.

Johnson, S. B., A. Warén, V. Tunnicliffe, C. V. Dover, C. G. Wheat, T. F. Schultz, and R. C. Vrijenhoek. 2014. Molecular taxonomy and naming of five cryptic species of Alviniconcha snails (Gastropoda: Abyssochrysoidea) from hydrothermal vents. Syst. Biodivers. 13: 278-295.

Kochevar, R. E., J. J. Childress, C. R. Fisher, and E. Minnich. 1992. The methane mussel: roles of symbiont and host in the metabolic utilization of methane. Mar. Biol. 112: $389-401$.

Koike, I., Y. Shirayama, T. Gamo, and H. Sakai. 1988. Respiration rate of Calyptogena soyoae obtained from the Calyptogena communities at the Hatsushima site. JAMSTEC J. Deep Sea Res. 4: 233-237. 
Lalou, C., J.-L. Reyss, E. Brichet, M. Arnold, G. Thompson, Y. Fouquet, and P. A. Rona. 1993. New age data for Mid-Atlantic Ridge hydrothermal sites: TAG and Snakepit chronology revisited. J. Geophys. Res.: Solid Earth 98: 9705-9713.

Maboloc, E. A., J. J. M. Puzon, and R. D. Villanueva. 2015. Stress responses of zooxanthellae in juvenile Tridacna gigas (Bivalvia, Cardiidae) exposed to reduced salinity. Hydrobiologia 762: 103-112.

Mickel, T. J., and J. J. Childress. 1982a. Effects of temperature, pressure, and oxygen concentration on the oxygen consumption rate of the hydrothermal vent crab Bythograea thermydron (Brachyura). Physiol. Zool. 55: 199-207.

Mickel, T. J., and J. J. Childress. 1982b. Effects of pressure and temperature on the ekg and heart rate of the hydrothermal vent crab Bythograea thermydron (Brachyura). Biol. Bull. 162: 70-82.

Mullineaux, L. S. 2014. Deep-sea hydrothermal vent communities. Pp. 383-400 in Marine Community Ecology and Conservation, M. D. Bertness, J. F. Bruno, B. R. Silliman and J. J. Stachowicz, eds. Sinauer Associates, Sunderland, Massachusetts, USA.

Nakamura, K., H. Watanabe, J. Miyazaki, K. Takai, S. Kawagucci, T. Noguchi, S. Nemoto, T.-o. Watsuji, T. Matsuzaki, T. Shibuya, et al. 2012. Discovery of new hydrothermal activity and chemosynthetic fauna on the Central Indian Ridge at $18^{\circ}-$ 20․․ PLOS ONE 7: e32965.

Norton, J. H., M. A. Shepherd, H. M. Long, and W. K. Fitt. 1992. The zooxanthellal tubular system in the giant clam. Biol. Bull. 183: 503-506.

Podowski, E. L., S. Ma, I. G. Luther, D. Wardrop, and C. R. Fisher. 2010. Biotic and abiotic factors affecting distributions of megafauna in diffuse flow on andesite and basalt along the Eastern Lau Spreading Center, Tonga. Mar. Ecol. Prog. Ser. 418: 2545.

Quetin, L. B., and J. J. Childress. 1980. Observations on the swimming activity of two bathypelagic mysid species maintained at high hydrostatic pressures. Deep-Sea Res., Part A 27: 383-391. 
R Core Team. 2017. $R$ : A language and environment for statistical computing. $\mathrm{R}$ Foundation for Statistical Computing, Vienna, Austria. URL: https://www.Rproject.org/. Accessed November 2017.

Ramirez-Llodra, E., T. M. Shank, and C. R. German. 2007. Biodiversity and biogeography of hydrothermal vent species: thirty years of discovery and investigations. Oceanography 20: 30-41.

\section{Rogers, A. D., P. A. Tyler, D. P. Connelly, J. T. Copley, R. James, R. D. Larter, K.} Linse, R. A. Mills, A. N. Garabato, R. D. Pancost, et al. 2012. The discovery of new deep-sea hydrothermal vent communities in the Southern Ocean and implications for biogeography. PLoS Biol. 10: e1001234.

Shank, T. M., D. J. Fornari, K. L. Von Damm, M. D. Lilley, R. M. Haymon, and R. A. Lutz. 1998. Temporal and spatial patterns of biological community development at nascent deep-sea hydrothermal vents ( $9^{\circ} 50^{\prime}$ N, East Pacific Rise). Deep Sea Res., Part II 45: 465-515.

Stewart, F. J., I. L. G. Newton, and C. M. Cavanaugh. 2005. Chemosynthetic endosymbioses: adaptations to oxic-anoxic interfaces. Trends Microbiol. 13: 439-448.

Suzuki, Y., R. E. Kopp, T. Kogure, A. Suga, K. Takai, S. Tsuchida, N. Ozaki, K. Endo, J. Hashimoto, Y. Kato, et al. 2006. Sclerite formation in the hydrothermalvent "scaly-foot" gastropod-possible control of iron sulfide biomineralization by the animal. Earth Planet. Sci. Lett. 242: 39-50.

Suzuki, Y., T. Sasaki, M. Suzuki, Y. Nogi, T. Miwa, K. Takai, K. H. Nealson, and K. Horikoshi. 2005. Novel chemoautotrophic endosymbiosis between a member of the Epsilonproteobacteria and the hydrothermal-vent gastropod Alviniconcha aff. hessleri (Gastropoda: Provannidae) from the Indian Ocean. Appl. Environ. Microbiol. 71: 5440-5450.

Takai, K., T.-o. Watsuji, J. Miyazaki, M. Miyazaki, C. Chen, A. Makabe, K. Motoki, A. D. Rogers, C. N. Roterman, L. Marsh, and J. Sigwart. 2016. R/V Yokosuka \& DSV Shinkai 6500 cruise report YK16-E02: Geochemical, geomicrobiological and biogeographical investigation of deep-sea hydrothermal activities in the Central and Southwestern Indian Ridges. JAMSTEC (Japan Agency for Marine-Earth Science and Technology) R/V Yokosuka Cruise Report 2016: Available from: 

http://www.godac.jamstec.go.jp/catalog/data/doc_catalog/media/YK16-E02_all.pdf. $661 \quad$ Accessed November 2017.

662 Van Dover, C. L., S. E. Humphris, D. Fornari, C. M. Cavanaugh, R. Collier, S. K. 663 Goffredi, J. Hashimoto, M. D. Lilley, A. L. Reysenbach, T. M. Shank, et al. 2001. 664 Biogeography and ecological setting of Indian Ocean hydrothermal vents. Science 665 294: 818.

666 Vermeij, G. J. 2013. The evolution of molluscan photosymbioses: a critical appraisal. 667 Biol. J. Linn. Soc. 109: 497-511.

668 Vermeij, G. J. 2016. Gigantism and its implications for the history of life. PLoS ONE 669 11: e0146092.

670 Warén, A., and P. Bouchet. 1993. New records, species, genera, and a new family of 671 gastropods from hydrothermal vents and hydrocarbon seeps. Zool. Scr. 22: 1-90.

672 Watanabe, H., and G. Beedessee. 2015. Vent fauna on the central Indian ridge. Pp. 205-

673212 in Subseafloor biosphere linked to hydrothermal systems : TAIGA concept, J.-i.

674 Ishibashi, K. Okino and M. Sunamura, eds. Springer, New York, USA.

675 Wittenberg, J.B. and Stein, J.L., 1995. Hemoglobin in the symbiont-harboring gill of 676 the marine gastropod Alviniconcha hessleri. Biol. Bull. 188: 5-7. 
Figure 1. Indian Ocean hydrothermal vent gastropods. A. The scalyfoot gastropod, Chrysomallon squamiferum, inside a respirometry chamber. The insertion of the fiber optic oxygen probe is visible at bottom. The animal is attached to the chamber floor and its head is extended, apparently exploring its surroundings. B. Alviniconcha marisindica, in a shipboard aquarium. C. Alviniconcha marisindica, attached to the wall of a respirometry chamber at $10{ }^{\circ} \mathrm{C}$.

Figure 2. Oxygen consumption rates of hydrothermal vent gastropods per gram wet tissue mass ( $\mu \mathrm{mol} \mathrm{O}_{2} / \mathrm{g} / \mathrm{hr}$ ), in Chrysomallon squamiferum and Alviniconcha marisindica. A. Mean mass-specific metabolic rates in each temperature group; error bars

690 indicate standard deviation and numbers within the bars show sample size per group, grey

691 bars are Alviniconcha marisindica (three temperature treatments), black bars are

692 Chrysomallon squamiferum (two temperature treatments). B. Log-log plot of mass-

693 specific metabolic rate of individual animals at $25^{\circ} \mathrm{C}$. Grey points are Alviniconcha

694 (diamonds are individuals from Kairei field, circles are individuals from Edmond field;

695 dashed line indicates the least-squares regression of a power scaling relationship for 696 allometric scaling of metabolism using all samples, $r=1.7 \mathrm{M}^{-0.25}$ for oxygen consumption

697 rate $r$ and mass $M$ ), black squares are Chrysomallon squamiferum, crosses are two

698 additional data points for other vent gastropod species with metabolic rates inferred at the 699 same experimental temperature (Henry et al., 2008).

\section{Supplementary Material}

703 Supplementary Video 1. The scaly-foot gastropod, Chrysomallon squamiferum, has a 704 large internal trophosome to house symbiotic bacteria, a large gill, and a large muscular 705 heart that pumps, as shown in this video of the live heartbeat. 